\title{
Operation of An Integrated 'All in One' Customized Batik Fabric Drying System for Traditional Cottage Operators in Kelantan
}

\author{
Sannasi. P \\ Faculty of Agro-Based Industry, \\ Universiti Malaysia Kelantan Jeli Campus, \\ 17600 Jeli, Kelantan, Malaysia
}

\begin{abstract}
This paper discusses the feasibility of the operating an integrated all in one customized batik fabric drying system for traditional local cottage operators in Kelantan. The proposed system has been collaboratively planned and designed with our industry partner, Kamaliah Batik Sdn Bhd. An integrated 'all in 1' customized drying room approach is presented with (1) an enclosed hang and dry oven room, equipped with heater, blower and filter; (2) four sets of mobile vertical hang and dry units; and (3) two units of mobile horizontal spread drying cabinet. The control module will be accessible by mobile phone application by the owner (addedvalue IoT feature). The proposed industry friendly system will significantly reduce time consuming individual labor-intensive work processes by $79 \%-91 \%$, help produce more completely dried fabric, increase the quantity of fabric that can be dried $(50 \%-60 \%$ increase), reduce cost and energy, and elevate overall batik productivity (up to $80 \%$ ).
\end{abstract}

Keywords-Dryer; drying time; evaporation; moisture; oven

\section{INTRODUCTION}

Batik manufacturing operators in the state of Kelantan, and along the East Coast of Peninsular Malaysia still thrive in present times by upholding the heritage of traditional batik production passed on from generation to generation. Batik is a unique art handicraft of various motifs or themes consisting of decorative shapes and design patterns expressed on fabric [1]. Batik manufacturing is a multi-step process activity. These include among others, fabric preparation, sketching, paraffin wax based 'canting', coloring, initial drying, color fixation and soaking, followed by secondary hang and dry action, continued with washing and rinsing, boiling, soaking for wax removal, series of rinsing, and final hang to dry practice. Finished batik fabric is used for making various wears and attires, uniforms, and for use in decorative items. In recent years, batik operators have begun to search and explore alternative options to further streamline and optimize routine work processes. Kamaliah Batik Sdn Bhd (KBSB) is a traditional batik manufacturing operator located at Kampung Pintu Geng, Kota Bharu, Kelantan. Through our collaboration, we have been informed that one of their main problem involves current drying practices which are too time consuming, done in batch process, less effective and inefficient drying, consumes large space but overall productivity is low. Moreover, it will affect fabric quality, and dependent upon sunny weather. This affects company productivity due to reduced total volume of batik fabric produced. At least 3 stages i.e. initial drying, secondary drying, and final drying require the need for a proper drying approach. Hence an innovative problem-based solution is needed to address the issues faced by the company. Many authors have agreed that drying is a complex, multi-factored, and energy intensive process [2]. These factors include simultaneous heat and mass transfer, moisture migration, and type of fabric. Findings by [3] suggested that drying is the limiting process in moisture management. Their work also indicated that drying rates are independent of fiber type in a constant-rate period. However, drying rates in the falling-rate period are dependent upon the type of fiber. According to [4], many methods can be used to remove water from fabric by evaporation. Amongst others are the contact method, steamsetting method, hydro-setting method, and heat-setting method. Hence, a study for an innovative approach is of necessity to decrease energy use, costs and environmental impact. In the case of batik, the technological and economical need is to develop and implement a more cost effective and efficient overall drying process scheme. In this paper we propose the implementation of a cost effective, user-friendly 'all in one' integrated batik fabric drying system. This will help solve issues related to batik fabric drying activity with an innovative customized approach. The formatter will need to create these components, incorporating the applicable criteria that follow.

\section{METHODOLOGY}

\section{A. Project Design}

The project design was based upon problem-based solution approach. Batik manufacturing is a multi-step process activity. The focus area for improvement is the shortcoming in the current drying practice.

\section{B. Limitation in Current Work Practice}

- (a) Time consuming after-rinse hanging and drying process.

- It was observed that at least 3 stages of drying were needed. The first was for initial drying (4-6 h), followed by secondary drying $(6-8 \mathrm{~h})$, and final drying, which can stretch up to 2 days. This calls for the need of a proper drying approach. Moisture accounts for nearly $40 \%(\mathrm{w} / \mathrm{w})$ of a recently rinsed cotton type batik fabric.

- (b) Limitation of working space for continuous hanging and drying (vertical hang, and horizontal spread). 
- A normal batik fabric measures $4.20 \mathrm{~m}$ by $1.14 \mathrm{~m}$. For vertical hang dry, the space between the fabrics are approximately $30 \mathrm{~cm}$. Whereas for horizontal spread drying, only one piece of fabric can be spread on the drying board frame at any one time.

- (c) Non-productive rope, string, wire and plank-based hang and dry practice.

- The batik fabric is hanged to dry manually by conventional rope, string, steel wire line tied to the wall or wood planks. This is a non-productive laborintensive practice. Moreover, fixed hang and dry approach restricts the drying process of large quantity of batik fabrics in a continuous period of time.

- (d) The burning of charcoal for drying.

- The current practice of burning charcoal to generate heat for drying leaves unfavorable smoke odor on the fabric.

- (e) Drying limitation during cloudy weather and rainy season.

- The other major limitation faced by the operator is the difficulty to dry the batik fabric during cloudy and rainy season.

This scenario affects company productivity due to reduced total volume of batik fabric produced. The important aspects for industrial practice are design, simulation, optimization, and process control. The five generic types of dryers [5] are presented in Figure 1.

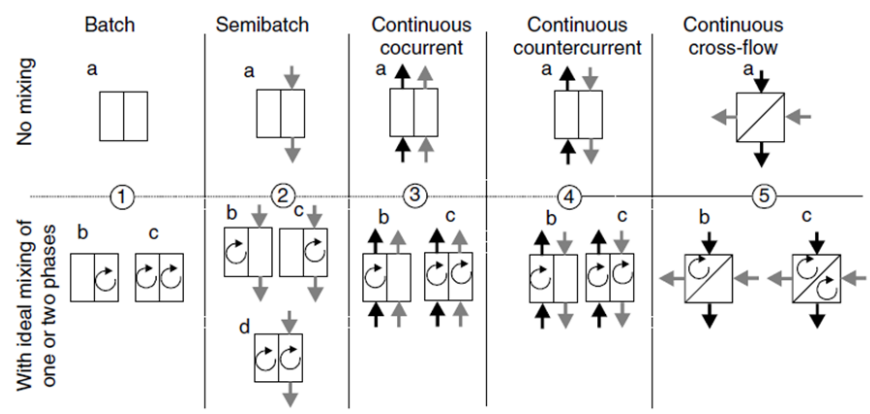

Fig. 1. Generic types of dryers [5]

\section{RESULTS AND DISCUSSION}

The conventional way to dry fabric is to hang dry. However, this practice is labor and time intensive which will affect productivity leading to reduced revenue for the operator. The principle of fabric drying is to transfer heat, and evaporating water molecules by hot air to reduce moisture content. Basic process calculations and simulations for drying are based on the principles presented previously by [5]. Drying rate is dependent upon energy transfer as heat which can occur as convection, conduction, or radiation or a combination of all effects [6]. Many types of dryers that differs in its design and types can be proposed. Among those are tray dryers, rotary dryers, roller dryers, fluidized bed dryers, spray dryers, dehydrators, oven dryers, spotlight dryers, etc. In our study we introduced an integrated 3 point 'all in 1' customized batik fabric drying system consisting of a (1) dryer oven room, (2) vertical hang and dry unit, and (3) horizontal spread drying cabinet will be implemented. Only stainless steel will be used for durability and better retention of heat. The control module will be accessible by mobile phone application by the owner (added-value IoT feature) The proposed industry friendly system will significantly reduce time consuming individual labor-intensive work processes, help produce more completely dried fabric, increase the quantity of fabric that can be dried, reduce cost and energy, and elevate overall batik productivity. The offerings are as follows:

- (1) The designated dryer oven room is as shown in Figure 2 with an improved open cycle dryer (air vented with heater pump) concept. Room dimension and accompanying specification design information is provided in Table 1 .

Table 1: Dimension and specification information of the dryer oven room

\begin{tabular}{|l|c|}
\hline Dimension and specification & Value \\
\hline Length: & $6 \mathrm{~m}$ \\
\hline Width: & $3 \mathrm{~m}$ \\
\hline Height: & $7 \mathrm{~m}$ \\
\hline Area: & $18 \mathrm{~m}^{2}$ \\
\hline Volume (room size): & $126 \mathrm{~m}^{3}$ \\
\hline Air changes per hour: & $1-2$ \\
\hline outside design temperature: & $35^{\circ} \mathrm{C}$ \\
\hline inside design temperature: & $70^{\circ} \mathrm{C}-80{ }^{\circ} \mathrm{C}$ \\
\hline Temperature difference: & $35^{\circ} \mathrm{C}-45^{\circ} \mathrm{C}$ \\
\hline Total transmission losses + air changes loss: & $47.84 \mathrm{~W} / \mathrm{h} /{ }^{\circ} \mathrm{C}$ \\
\hline Total heating requirement: & $3,013 \mathrm{~W} / \mathrm{h}-3492 \mathrm{~W} / \mathrm{h}$ \\
\hline
\end{tabular}

Transmission losses is included for the oven opening with an area of $18 \mathrm{~m}^{2}$. Mass transfer balance, evaporation rate modelling was carried out with room heating calculator [7]. In order to prevent heat loss, insulated walls (stainless steel with rockwool foam will be used. The room will be equipped with heater $(1.1-1.3 \mathrm{~kW})$, blower $(0.3 \mathrm{~kW})$ at the distribution outlet, and air filter at the outlet. Hot air circulation and flow will be in a closed loop system, driven by two three-phase asynchronous motors ( $2.2 \mathrm{~kW}$; with one spare unit), and the outlet connected to a pair of nozzles. Humidity level and air circulation in the room will be constantly monitored. The semi-empirical model will be based on mass balance and moisture balance transfer equations between the fabric and circulating hot air. An active regulator will be in place. After the radiator is heated, the hot air is sucked into the fan, and channeled into the dryer compartment. The continual running of the process will create and deliver pressurized air into the drying compartment. Heat efficiency is dependent upon the initial heating up process, heat concentration and heat consumption. Ambient temperature is taken as $35{ }^{\circ} \mathrm{C}$. The temperature in the dryer oven will be in the range of $70{ }^{\circ} \mathrm{C}-80$ ${ }^{\circ} \mathrm{C}$ (temperature difference of $35^{\circ} \mathrm{C}-45^{\circ} \mathrm{C}$ ). These combined factors will dictate the overall length of the drying time. As reported by [8], drying time is highly influenced by air flow and direction, pressure fluctuations, as well the temperature of the air entering the inlet. 


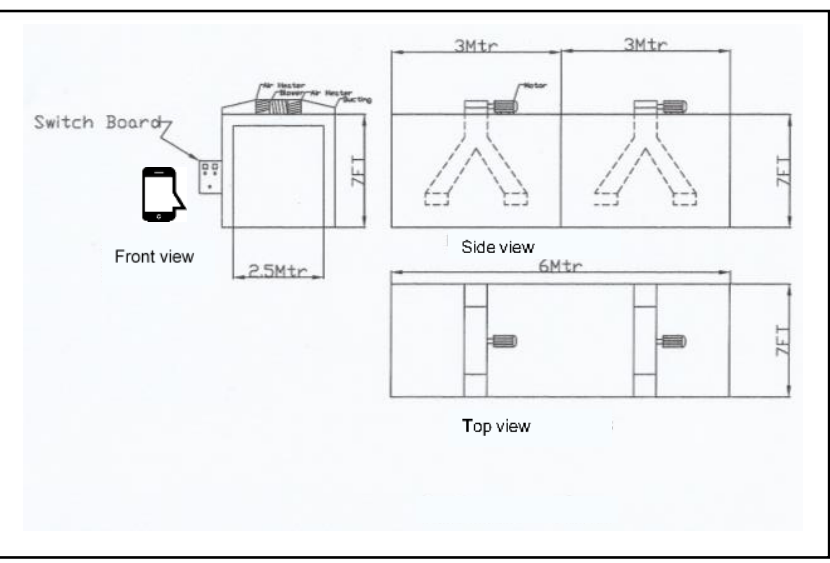

Fig. 2. Dryer oven schematic for dryer room set-up

The added value feature incorporated in setting up the dryer room is as follows: (i) Innovation for cost saving measures. This is achieved by adopting a 2 in 1 function with existing air conditioning unit for waste heat capture and recovery. There are two existing $1 \mathrm{HP}$ air-conditioning units at the premise adjacent to the proposed dryer oven room area. For cost and energy saving, an innovative waste heat recovery and sharing duct system will be put in place, where the hot air from the air conditioning condenser will be directed into the drying room as well. Condenser temperature was measured at $\sim 47{ }^{\circ} \mathrm{C}$. There is a gain of $12{ }^{\circ} \mathrm{C}$ compared to ambient temperature $\left(35^{\circ} \mathrm{C}\right)$ that could reduce the amount of energy required to raise the temperature in the dryer oven. The heater will auto shut off when the desired oven temperature is attained. (ii) The switch board control module can also be accessed via mobile application (IoT feature). Through the use of sensors, the owner can monitor and control the temperature, humidity, air flow, power, and operation of the unit. Data can be pooled for monthly analysis.

- (2) The dryer oven room can accommodate 2 vertical hang and dry units at any one time (Figure 3). An additional 2 units will be placed outside to take on the next batch of fabrics. The unit will hold series of hang rails to optimize size and cater for increased number of batik fabric for drying. The space between the fabrics being dried can be reduced to $10 \mathrm{~cm}$. More fabrics can be hanged by this way. This will facilitate continuous drying work flow and increase efficiency and productivity.

- (3) For the purpose of spread fabric drying, two units of mobile horizontal drying cabinet is also proposed (Figure 4). The spread drying process will allow higher drying rate as more uniform air flow can cover the width and length of the fabric more efficiently. [4] have noted the issue with obtaining air flow distribution uniformly when using hot air nozzle system for fabric drying. These unit consists of multi racks with individual trays. More fabrics can be spread, and any wet drips will fall into the tray below without affecting the other fabrics. The racks and trays are movable. The cabinet will be brought into the dryer oven room for further drying. Cabinet mobility is achieved with rollers to facilitate smooth movement within the premise.

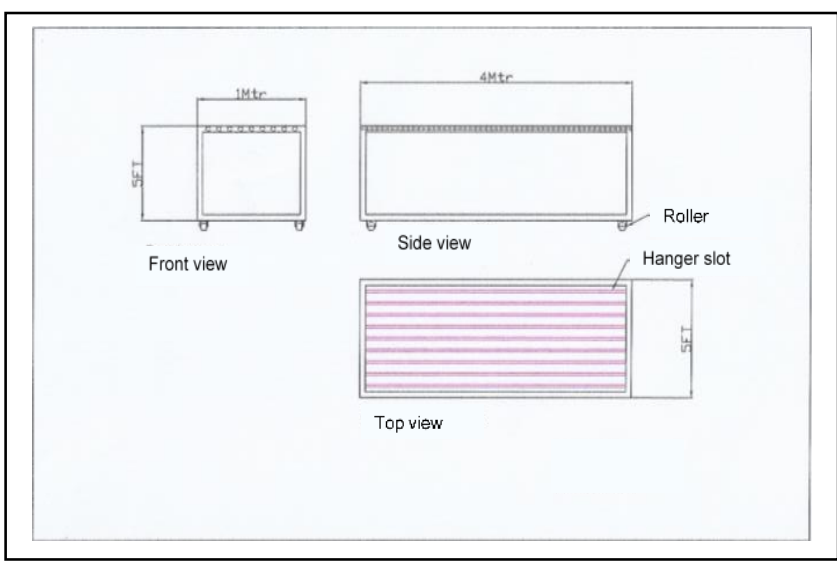

Fig. 3. Dryer oven schematic for dryer room set-up

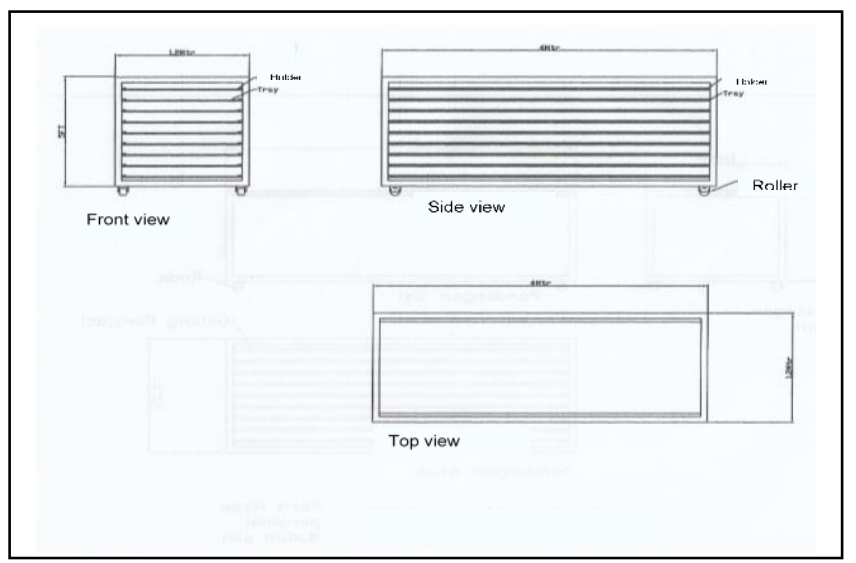

Fig. 4. Dryer oven schematic for dryer room set-up

The delivery of an integrated 'all in one' customized batik fabric drying system will address and solve the issues faced by the company and help increase productivity to meet market demand (Table 2). Furthermore, this system can be installed within the available premise space and will not interfere with existing production process. Emphasis is on energy and cost saving, structure simplicity and continuous operation capability, as well as convenient maintenance without the need for hiring high skilled operator. In addition, the rinse water will be channeled to the existing active filtering drain trap system available at the premise for treatment, recovery, and reuse. The whole process reflects the sustainability theme for a green industrial work process. The overall performance can be reflected in terms of increased yield or the number of fabrics produced, while keeping the production cost at a minimum. This is apparent as drying is a highly energyintensive operation. The integrated system will support the green technology thrust in the production of batik. Previously [1] have discussed the option of using solar heating system. However, this option can have limitations when it comes to having sunny weather as the East Coast of Peninsular Malaysia is subject to prolonged monsoon every year end. 


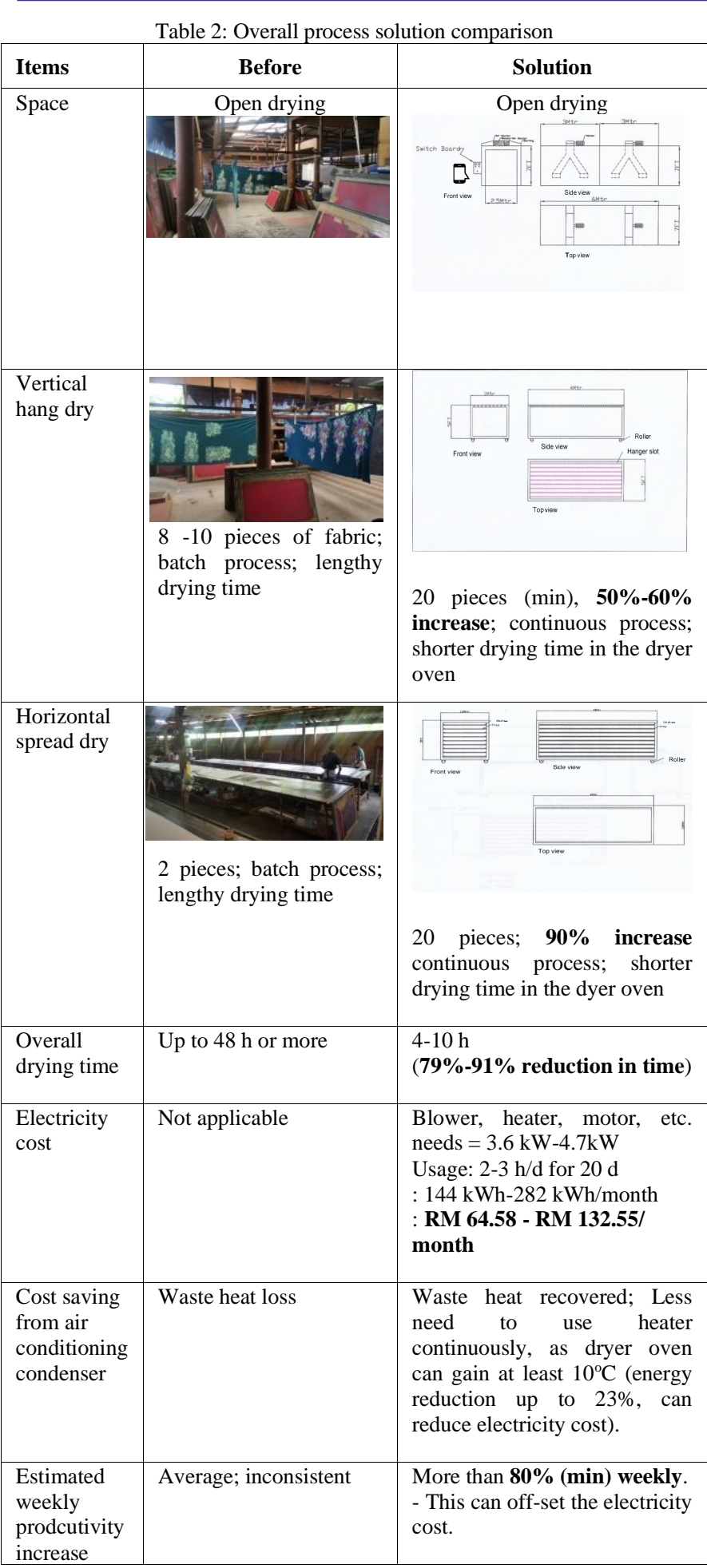

As seen from Table 2, significant changes can be observed with this approach. The vacant space will now be occupied by the oven dryer room. The previous vertical hang dry practice can only cater for 8-10 pieces of fabric at any one time. With the introduction of the mobile vertical hang and dry unit, the capacity is now increased up to 50\%-60 ( 20 pieces of fabric). The horizontal spread dry will see a marked increase of up to $90 \%$ as opposed to only 2 pieces before. And all the processes can be done in a relatively shorter period of time continuously.

Energy consumption is the most important factor of concern in day to day operation. As most cottage industry operators depend mostly upon local order, any intervention or innovation implementation must not only be practical but economically feasible as well. Drying process is not only time consuming but also an energy intensive activity that will affect the overall textile finishing operations [8]. In addition, any inclusion of high technology driven machinery which would require heavy initial investment with periodical maintenance will not be favored.

\section{CONCLUSION}

The integrated system comprises of a designated dryer oven room with an integrated heater dryer system, mobile vertical hang and dry units, and mobile horizontal spread drying cabinets. Based on fabric quantity output and optimization of space, and time (79\%-91\%), this allows for continuous process run. By that, overall weekly productivity is projected to increase up to $80 \%$ ( $\mathrm{min}$ ) to meet market demand.

\section{ACKNOWLEDGMENT}

The author thanks En. Khairul Annuar B. Hj. Mohamed Idrus, the Manager of Kamaliah Batik Sdn Bhd for the problem insight and collaboration opportunity.

\section{REFERENCES}

[1] R. Syahputra and I. Soesnti, "Application of green energy for batik production process”, J Theo Appl Info Technol., Vol 91(2), pp 249 $256,2016$.

[2] H. Baxi, A. Patel and J. Barve, "Modelling and simulation of dryer system”, 2015 International Conference on Industrial Instrumentation and Control (ICIC). Pune, pp 1544-1549, 2015. Doi: 10.1109/IIC.2015.7150995.

[3] K. Gurudatt, V.M. Nadkarni and K.C. Khilar, "A study on drying of textile substrates and a new concept for the enhancement of drying rate", J Textile Inst, Vol 101(7),pp 635-644, 2010.

[4] K.D. Patel, "A review - hot air nozzle system of textile dryer", Int J Adv Res Innov Ideas in Edu, Vol 3(2), pp 3829-3833, 2017.

[5] Z. Pakowski amd A.S. Mujumdar, "Basic process calculations and simulations in drying", in Handbook of Industrial Drying, A.S Mujumdar, Eds. Boca Raton: CRC Press, pp. 54-79, 2007.

[6] S.B. Mali and M.C. Butale, "A review paper on different drying methods"' Int J Eng Res Technol, Vol 8(5), pp. 211-216, 2019.

[7] Chromalox, "Room heating calculator", accessed from https://www.chromalox.com/Resources/Support/calculators/comfortheater.aspx, 2019

[8] G. Galoppi, L.Ferrari, G. Ferrara, and E.A. Carnevale, "Experimental investigation on industrial drying process of cotton yarn bobbins: energy consumption and drying time"' Energy Proc, Vol 126, 361-36, 2017 